\title{
Breast cancer risk in a rapidly aging population: advances and approaches to study the aging tissue microenvironment
}

This article was published in the following Dove Medical Press journal:

Breast Cancer - Targets and Therapy

\section{Steven J Greco}

Department of Medicine, Division of Hematology and Oncology, RutgersNew Jersey Medical School, Newark, NJ, USA
Correspondence: Steven J Greco Rutgers New Jersey Medical School, Medical Sciences Building Room E-543, I 85 South Orange Avenue, Newark, NJ 07103, USA

Email grecost@njms.rutgers.edu
Aging is the predominant risk factor for most chronic diseases, and is the primary cause of morbidity and mortality in the developed world. The rapidly increasing rate of global aging poses significant economic concern to the current health care model. A better understanding of the biology of aging is necessary to yield new approaches that extend the human "health span" and delay the onset of age-related disease. These approaches would address the underlying mechanisms of disease, rather than treat their symptoms individually.

Diseases most commonly identified as related to aging include Alzheimer's disease, cardiovascular disease, diabetes, infectious diseases such as influenza, and stroke. However, it has also been firmly established that aging is significantly linked to the incidence of many cancers, including breast cancer. ${ }^{1}$ Despite an increasing trend toward early diagnosis and improved standard of care, breast cancer remains a clinical problem. Breast cancer cells can remain dormant for decades before clinical detection, and can survive as dormant cells during periods of cancer remission. ${ }^{2}$ Breast cancer resurgence and metastasis following these extended periods of dormancy is predictive for poor patient prognosis, thereby making breast cancer-related mortality coincident with chronological age. ${ }^{3}$ Although most new breast cancer diagnoses occur in women less than 65 years of age, most breast cancer deaths occur in women aged 65 years and older. ${ }^{1}$ Further, while the overall survival rates for breast cancer patients have gradually increased over the last two decades, a similar trend has not been observed for women of 65 years and older. ${ }^{4,5}$ This may be attributed to diagnosis at a later stage of the disease for aged individuals compared to those under 65 years, or to less frequent administration of adjuvant therapy to this demographic for fear of toxicity, tolerability, and impact on quality-of-life. ${ }^{6,7}$ Interestingly, at the time of diagnosis, aged patients typically present with smaller tumors, less lymph node involvement, and tumors that are hormone receptor positive and human epidermal growth factor receptor (HER-2) negative ${ }^{8,9}$ Unfortunately, these favorable tumor characteristics in aged patients have not translated into increased overall survival.

Mechanistically, chronic disease is partly driven by a gradual decline in cellular homeostasis within the aging tissue microenvironment. ${ }^{10}$ Over time, this decline ultimately leads to tissue dysfunction and the manifestation of disease. ${ }^{10}$ The bone marrow has been shown to be a major site of breast cancer cell micrometastasis and dormancy, with evidence of the bone marrow as the source organ during cancer resur- 
gence decades following remission. ${ }^{3}$ Once breast cancer cells spread to the bone marrow, survival rates of cancer patients significantly decline. Bone marrow is a heterogenous, complex organ containing a dynamic cornucopia of cell types, including mesenchymal stem cells, adipocytes, osteoblasts, hematopoietic stem and progenitor cells, osteoclasts, macrophages, lymphoid cells, endothelial cells, and nerve cells. ${ }^{11}$ Over time, the changing architecture of the aging bone marrow microenvironment increases the probability of breast cancer cell exit from dormancy, metastatic resurgence, and decreased overall survival. A better understanding of how these age-related changes in the bone marrow "metastatic niche" lead to breast cancer resurgence is necessary to facilitate the development of new therapies targeting breast cancer metastasis. Such therapies will have to account for the complexity of the bone marrow niche and its many different cell types, as well as the proteins they secrete and the supportive extracellular matrix. ${ }^{12}$ One important consideration in therapeutic development is that the therapy not disrupt homeostatic function of the normal tissue microenvironment. The proximity of the hematopoietic system to the "metastatic niche" has made such development a difficult obstacle to overcome.

Breast cancer cell dormancy enables the tumor cells to survive and evade the immune response. This characteristic has driven new research investigating whether dormant breast cancer cells can be targeted with immunotherapy, either alone or in combination with chemotherapy. ${ }^{13}$ Early clinical trials have shown that immune checkpoint inhibitors have promise in breast cancer treatment. These findings demonstrate the clinical benefit of exploiting the patient's immune system to target the disease. ${ }^{14}$ However, the immune system must be viewed as a double-edged sword. In contrast to the clear promise of immune therapy in treating breast cancer, the aging immune system becomes chronically inflammatory, a phenomenon often referred to as inflamm-aging. ${ }^{15}$ The increase in an aged individual's systemic pro-inflammatory status with age is a major contributor to cancer progression and overall survival. ${ }^{16-18}$ These findings open further avenues for immuno-therapeutic development to target age-related breast cancer.

The aging neuropsychological system also contributes to breast cancer incidence and resurgence in the aging population. The bone marrow is an innervated organ which interacts with the hypothalamic-pituitary-adrenal (HPA) axis. Individuals with dormant breast cancer in the bone marrow are susceptible to factors affecting neuropsychological status, such as psychological stress. Stress is an unavoidable consequence of daily life, with chronic stress exposure qualitatively linked to breast cancer incidence. ${ }^{19}$ Stress induces inflammation and is disease permissive. With psychological stress, the parasympathetic nervous system and HPA axis are suppressed so that their anti-inflammatory status is abrogated. ${ }^{20}$ This effect of chronic psychological stress, combined with the age-related increase in chronic inflammation, illustrates the important relationship between the nervous and immune systems in regulating cancer incidence and progression in aged individuals.

In this thematic issue on breast cancer and aging, a number of experts in the field have contributed original publications and comprehensive reviews on the topics discussed above. Crone et al have reported on the anti-estrogenic effects of the herbal remedy, black cohosh, on BRCA1 and steroid receptors in breast cancer cells. ${ }^{21}$ Black cohosh is often used by women to treat symptoms associated with menopause. Treatment of breast cancer cells with black cohosh was observed to decrease proliferation, with an enhancing effect observed in combination with estrogen. Ozdemir et al here present an algorithm to choose an optimal breast cancer preventative agent in older women. The group performed a study observing outcomes for 23 older adult females being treated with one of four different chemopreventive agents. ${ }^{22}$ The authors found that the outcomes of initial utilization of the chemopreventive agent choice algorithm support the viability of the protocol. Tremmel et al examined thyronamine regulation of TAAR1 expression in breast cancer cells and investigated its influence on viability and migration. A significant upregulation of TAAR1 induced by stimulation with T1AM was observed, with TAAR1-related cell transduction mechanisms viewed as a potential target for breast cancer patients. ${ }^{23}$ Ayoub et al provide a comprehensive review of recent advances and combination therapeutic approaches in immunotherapy for HER2-positive breast cancers. ${ }^{24}$ The authors survey how immunotherapy has dramatically advanced the field of cancer treatment, and discuss how the approach has emerged as a promising targeted treatment in breast cancer. To date, no immunotherapy has been approved so far for preventive or therapeutic treatments in breast cancer.

The series seeks to understand the complexity of agerelated development of breast cancer, particularly in the context of the mammary gland and other tissue microenvironments. It will serve as an important translational resource to both researchers and clinicians interested in age-related cancers. 


\section{Acknowledgments}

The work was supported by an award given by the US Department of Defense, W81XWH-11-1-0276. This work was supported by a grant from the US Department of Defense.

\section{Disclosure}

The author reports no conflicts of interest in this work.

\section{References}

1. Karuturi M, VanderWalde N, Muss H. Approach and management of breast cancer in the elderly. Clin Geriatr Med. 2016;32(1): 133-153.

2. Dittmer J. Mechanisms governing metastatic dormancy in breast cancer. Semin Cancer Biol. 2017;44:72-82.

3. Braun S, Vogl FD, Naume B, et al. A pooled analysis of bone marrow micrometastasis in breast cancer. $N$ Engl J Med. 2005;353(8): 793-802.

4. Smith BD, Jiang J, McLaughlin SS, et al. Improvement in breast cancer outcomes over time: are older women missing out? J Clin Oncol. 2011;29(35):4647-4653.

5. Early Breast Cancer Trialists' Collaborative Group (EBCTCG), Clarke M, Coates AS, et al. Adjuvant chemotherapy in oestrogen-receptor-poor breast cancer: patient-level meta-analysis of randomised trials. Lancet. 2008;371(9606):29-40.

6. Lyratzopoulos G, Abel GA, Brown CH, et al. Socio-demographic inequalities in stage of cancer diagnosis: evidence from patients with female breast, lung, colon, rectal, prostate, renal, bladder, melanoma, ovarian and endometrial cancer. Ann Oncol. 2013;24(3):843-850.

7. Owusu C, Lash TL, Silliman RA. Effect of undertreatment on the disparity in age-related breast cancer-specific survival among older women. Breast Cancer Res Treat. 2007;102(2):227-236.

8. Diab SG, Elledge RM, Clark GM. Tumor characteristics and clinical outcome of elderly women with breast cancer. J Natl Cancer Inst. 2000;92(7):550-556.

9. Daidone MG, Coradini D, Martelli G, Veneroni S. Primary breast cancer in elderly women: biological profile and relation with clinical outcome. Crit Rev Oncol Hematol. 2003;45(3):313-325.
10. López-Otín C, Blasco MA, Partridge L, Serrano M, Kroemer G. The hallmarks of aging. Cell. 2013;153(6):1194-1217.

11. Shiozawa Y, Eber MR, Berry JE, Taichman RS. Bone marrow as a metastatic niche for disseminated tumor cells from solid tumors. Bonekey Rep. 2015;4:689.

12. Place AE, Jin Huh S, Polyak K. The microenvironment in breast cancer progression: biology and implications for treatment. Breast Cancer Res. 2011;13(6):227.

13. Emens LA. Breast cancer immunotherapy: facts and hopes. Clin Cancer Res. 2018;24(3):511-520.

14. Emens LA, Kok M, Ojalvo LS. Targeting the programmed cell death-1 pathway in breast and ovarian cancer. Curr Opin Obstet Gynecol. 2016;28(2):142-147.

15. Bonafè M, Storci G, Franceschi C. Inflamm-aging of the stem cell niche: breast cancer as a paradigmatic example: breakdown of the multi-shell cytokine network fuels cancer in aged people. Bioessays. 2012;34(1):40-49.

16. Emens LA, Ascierto PA, Darcy PK, et al. Cancer immunotherapy: opportunities and challenges in the rapidly evolving clinical landscape. Eur J Cancer. 2017;81:116-129.

17. Emens LA. Breast cancer immunobiology driving immunotherapy: vaccines and immune checkpoint blockade. Expert Rev Anticancer Ther. 2012;12(12):1597-1611.

18. Cimino-Mathews A, Foote JB, Emens LA. Immune targeting in breast cancer. Oncology. 2015;29(5):375-385.

19. Chiriac VF, Baban A, Dumitrascu DL. Psychological stress and breast cancer incidence: a systematic review. Clujul Med. 2018;91(1):18-26.

20. Straub RH, Cutolo M. Psychoneuroimmunology-developments in stress research. Wien Med Wochenschr. 2018;168(3-4):76-84.

21. Crone M, Hallman K, Lloyd V, et al. The antiestrogenic effects of black cohosh on BRCA1 and steroid receptors in breast cancer cells. Breast Cancer (Dove Med Press). In press 2019.

22. Ozdemir BZ, Goodin JB, Bodenner DL. Breast cancer prevention in older women: an algorithm to choose an optimal preventive agent Breast Cancer (Dove Med Press). In press 2019.

23. Tremmel E, Hofmann S, Kuhn C, et al. Thyronamine regulation of TAAR1 expression in breast cancer cells and investigation of its influence on viability and migration. Breast Cancer (Dove Med Press). In press 2019.

24. Ayoub NM, Al-Shami KM, Yaghan RJ. Immunotherapy for HER2positive breast cancer: recent advances and combination therapeutic approaches. Breast Cancer (Dove Med Press). 2019;11:53-69.

Dove Medical Press encourages responsible, free and frank academic debate. The content of the Breast Cancer: Targets and Therapy 'Editorial' section does not necessarily represent the views of Dove Medical Press, its officers, agents, employees, related entities or the Breast Cancer: Targets and Therapy editors. While all reasonable steps have been taken to confirm the content of each Editorial, Dove Medical Press accepts no liability in respect of the content of any Editorial, nor is it responsible for the content and accuracy of any Editorial.

Breast Cancer - Targets and Therapy

\section{Publish your work in this journal}

Breast Cancer - Targets and Therapy is an international, peerreviewed open access journal focusing on breast cancer research, identification of therapeutic targets and the optimal use of preventative and integrated treatment interventions to achieve improved outcomes, enhanced survival and quality of life for the cancer patient.
Dovepress

The manuscript management system is completely online and includes a very quick and fair peer-review system, which is all easy to use. Visit http://www.dovepress.com/testimonials.php to read real quotes from published authors. 